\title{
Contribution of three-dimensional conformal intensity-modulated radiation therapy for women affected by bulky stage II supradiaphragmatic Hodgkin disease
}

\author{
Delphine Antoni ${ }^{1}$, Shanti Natarajan-Ame ${ }^{2}$, Philippe Meyer ${ }^{1}$, Claudine Niederst ${ }^{1}$, Khalil Bourahla ${ }^{3}$ \\ and Georges Noel ${ }^{1 *}$
}

\begin{abstract}
Purpose: To analyze the outcome and dose distribution of intensity-modulated radiation therapy (IMRT) by helical tomotherapy in women treated for large supradiaphragmatic Hodgkin's disease.

Material and methods: A total of 13 patients received adjuvant radiation at a dose of $30 \mathrm{~Gy}$ to the initially involved sites with a boost of $6 \mathrm{~Gy}$ to those areas suspected of harboring residual disease on the simulation CT scan.

Results: With a median follow-up of 23 months, the two-year progression-free survival was 91.6\%, and the 2- and 3 -year overall survivals were $100 \%$. We did not report any heart or lung acute side effects. The conformity index of PTV (Planning Target Volume) was better for IMRT than for 3D-CRT ( $p=0.001$ ). For the breasts, lungs, heart, thyroid and esophagus, the volume distributions favored the IMRT plans. For the breasts, the $V_{20 G y}, V_{25 G y}$ and $V_{30 G y}$ were $1.5,2.5$ and 3.5 times lower, respectively, for IMRT than for 3D-CRT. For the lung tissues, the $V_{20 G y}$ and $V_{30 G y}$ were 2 times and 4.5 times lower, respectively, for IMRT than for 3D-CRT. For the heart, the $V_{20 G y}$ and $V_{30 G y}$ were 1.4 and 2 times lower, respectively, for IMRT than for 3D-CRT. For the esophagus, the $V_{35 G y}$ was 1.7 lower for IMRT than for 3D-CRT, and for the thyroid, the $V_{30 G y}$ was 1.2 times lower for IMRT.

Conclusion: IMRT by helical tomotherapy improved the PTV coverage and dramatically decreased the dose in organs at risk. The treatment was well tolerated, but a longer follow-up is necessary to prove a translation of these dosimetric improvements in the outcome of the patients.
\end{abstract}

Keywords: Hodgkin's lymphoma, IMRT, Dose distribution

\section{Introduction}

Early-stage Hodgkin lymphoma treated with a combination of chemotherapy and radiotherapy has an excellent clinical outcome, with overall survival reaching 90\% [1-4]. However, late effects can dramatically affect the quality of life or be life-threatening in these survivors [5]. These late complications, including cardiovascular effects and secondary cancer, are due to large radiation doses and fields and also to chemotherapy, both of which lead to cardiovascular toxicity [6,7] and increase

\footnotetext{
*Correspondence: gnoel@strasbourg.unicancer.fr

'Radiotherapy department, Centre de lutte contre le Cancer Paul Strauss, 3, rue de la Porte de l'Hôpital, Strasbourg Cedex BP 42, 67065, France Full list of author information is available at the end of the article
}

the risk of secondary cancer [6,8-11]. Depending on the follow-up, the incidence rate ranges from $4.6 \%$ to $20 \%$ [10,12-17]. The incidence of hematologic cancers is the most important, with standardized incidence ratios (SIRs) between 1.5 and 30 times higher than for solid tumors $[10,11,18]$. The occurrence of a secondary cancer is more frequent for women than men $[10,19]$, mainly because of secondary breast cancers. Several risk factors have been associated with radiation-induced breast cancers, such as the age at treatment [20], higher irradiation dose [21,22] and the irradiation volumes $[16,22]$.

Because radiotherapy remains a cornerstone in the treatment of Hodgkin lymphoma, some improvements have been developed recently to decrease the risk of side

\section{C) Biomed Central}


effects: i) decreasing the delivered dose, ii) irradiating the initially involved fields, and iii) using modern radiation techniques, such as intensity-modulated radiation therapy (IMRT) [2,3,23-26]. The decrease in the irradiated volume in the breasts could potentially decrease the risk of secondary breast cancer, thereby improving the prognosis in these patients [8]. We propose to demonstrate that using the helical tomotherapy HiArt system can achieve both the goal of improving the dose distribution to large or bulky PTV and that of sparing organs at risk compared with $3 \mathrm{D}$ radiation therapy (3D-RT) in young women who are particularly at risk for secondary breast cancer. We present the results of this study comparing dosimetric plans for 3D-conformal radiation therapy (3D-CRT) and for IMRT by helical tomotherapy (IMRT-HT) in women with Hodgkin disease.

\section{Materials and methods}

\section{Patients and methods}

A total of 13 patients with a median age of 29.7 years (17-53 years) at diagnosis were treated for newly diagnosed supradiaphragmatic stage II Hodgkin's disease. Twelve patients had stage IIA, and one had stage IIB. All patients had cervical and mediastinal lymph node involvement. The initially involved nodal areas were described according to Mountain and Dresler's international classification [27] for mediastinal node areas and the Gregoire et al. classification for head and neck node involvement [28]. Internal mammary chain and axillary lymph nodes were involved in four patients (Table 1). All patients received chemotherapy containing adriamycin, bleomycin, vinblastine and dacarbazine (ABVD): 1 patient received 3 cycles, 9 patients received 4 cycles, and 2 patients received 6 cycles. One additional patient was treated with 2 cycles of ABVD followed by 2 cycles of BEACOPP (bleomycin, etoposide, adriamycin, cyclophosphamide, vincristine, procarbazine and prednisone).

\section{Simulation}

A customized immobilization mask was used for all patients. The patients underwent two virtual simulations on a dedicated computed tomography (CT) instrument (General Electric ${ }^{\mathrm{TM}}$ Lightspeed QXI) using $3.75 \mathrm{~mm}$ slices. The first was performed before any chemotherapy with contrast enhancement, and the second, without injection, was performed 15 days after the completion of the chemotherapy and 15 days before the start of radiotherapy; the same position and mask (no masks were remade) were used. The CTs were performed using a free breath schedule; patients were placed in the supine position with both arms along the body. Furthermore, all the patients underwent an ${ }^{18}$ F-FDG-PET scan with $3.27 \mathrm{~mm}$ slices before any treatment (General Electric Discovery ST); this scan was used for simulation and delineation. The position for the PET scan was equivalent to that used for the simulation CTs.

\section{Volume definition}

The pre-chemotherapy CT and PET were fused with the pre-RT CT. Contouring was performed with Focal (Elekta AB, Stockholm, Sweden) for 3D-CRT and IMRT-HT. The clinical target volume (CTV) and planning target volume (PTV) were determined according to INRT guidelines $[29,30]$. The PTV was obtained by adding $1-\mathrm{cm}$ isotropic margins to the clinical target volume [30]. The ${ }^{18}$ F-FDGPET scan was used to improve the detection of initially involved lymph nodes [31]. The organs at risk (OARs) were delineated, including the heart, spinal cord, thyroid, esophagus, lungs and breasts.

\section{Treatment planning and dosimetric parameters}

The dosimetries were calculated using the Xio (Elekta AB, Stockholm, Sweden) and Tomotherapy planning systems (Tomotherapy Incorporated, Madison, WI, USA). The dosimetric comparison was performed with Artiview (Aquilab, Lille, France).

The radiotherapy delivered 30 Gy in 15 fractions of 2 Gy, five days a week to PTV $\mathrm{PVGy}_{30}$, with boost of 6 Gy in three fractions of 2 Gy to $\mathrm{PTV}_{36 \mathrm{~Gy}}$. The PTV was planned to receive at least $95 \%$ of the prescribed dose according to ICRU 50 and 62 [32,33]. For both the 3D-CRT and IMRT plans, the data were collected with respect to the median (D50\%), near-max (D2\%) and near-min (D98\%) doses according to the ICRU 83 [34]. The conformity (CI), homogeneity $(\mathrm{HI})$ and coverage $(\mathrm{CO})$ indices of the plans were calculated [35]. The CI was defined by the ratio between the reference isodose volume (RIV) and the PTV, and the HI was defined by the ratio between D2\% (near-max dose) received by the target volume and the reference dose. We also compared the coverage index $(\mathrm{CO})$ corresponding to the ratio between D98\% (near-min dose) received by the target volume and the reference dose. The $V_{5 G y}, V_{20 G y}$ and $\mathrm{V}_{30 \text { Gy }}$ for both lungs minus the PTV were limited, respectively, to $60 \%, 30 \%$ and $20 \%$ [36-40]. The dose limits also included a maximal spinal cord dose limit $<45$ Gy and a mean heart dose $<20$ Gy. For the breast, the median, mean, maximal and minimal doses and the volumes receiving total doses of 1 to 36 Gy were recorded for each breast and for a volume summing both volumes.

The 3D-CRT field set-up was performed with two opposed parallel antero-posterior fields equally powered with 6 and $25 \mathrm{MV}$ photon beams. For the IMRT, the field width, pitch and modulation factors for the treatment planning optimization were 2.5 to $5 \mathrm{~cm}, 0.287$ and 2.5 , respectively.

\section{Follow-up}

The patients were seen in consultation every two months during the first year and every four months during the $2^{\text {nd }}$ and $3^{\text {rd }}$ years. CT and PET scans were performed at least every six months. A lung function test (LFT) and cardiac 
Table 1 Involved lymph nodes areas (X) and those suspects of no sterilization after chemotherapy (Xo)

\begin{tabular}{|c|c|c|c|c|c|c|c|c|c|c|c|c|c|c|}
\hline Lymph node areas & & Patient 1 & Patient 2 & Patient 3 & Patient 4 & Patient 5 & Patient 6 & Patient 7 & Patient 8 & Patient 9 & Patient 10 & Patient 11 & Patient 12 & Patient 13 \\
\hline \multirow[t]{8}{*}{ Cervical lymph node areas } & $2 \mathrm{R}$ & & & & & $\mathrm{x}$ & & & $x$ & & Xo & & & \\
\hline & $3 R$ & $x$ & & & & Xo & Xo & & $x$ & & $x$ & & $x$ & \\
\hline & $4 \mathrm{R}$ & $x$ & Xo & & & Xo & Xo & $x$ & Xo & & Xo & $\mathrm{x}$ & Xo & $\mathrm{x}$ \\
\hline & $5 R$ & $x$ & & & & $x$ & & & Xo & & $x$ & & & \\
\hline & $2 \mathrm{~L}$ & Xo & & & & & & & & & $x$ & & & \\
\hline & $3 L$ & Xo & & & $\mathrm{x}$ & & $\mathrm{x}$ & & & $x$ & Xo & & & \\
\hline & $4 \mathrm{~L}$ & Xo & & Xo & Xo & & Xo & Xo & $x$ & $x$ & Xo & Xo & Xo & Xo \\
\hline & $5 \mathrm{~L}$ & $x$ & & Xo & & & & & & $x$ & & $\mathrm{x}$ & & \\
\hline \multirow[t]{15}{*}{ Mediastinal lymph node areas } & $1 \mathrm{R}$ & Xo & Xo & Xo & & Xo & $\mathrm{X}$ & & & $x$ & & $\mathrm{x}$ & $x$ & $\mathrm{x}$ \\
\hline & $2 \mathrm{R}$ & Xo & Xo & Xo & Xo & Xo & $\mathrm{X}$ & & & $x$ & $x$ & $x$ & $x$ & $x$ \\
\hline & $1 \mathrm{~L}$ & Xo & & $x$ & Xo & $x$ & $x$ & & & & & $x$ & $x$ & $x$ \\
\hline & $2 \mathrm{~L}$ & Xo & & $x$ & & $\mathrm{X}$ & $\mathrm{X}$ & & $x$ & & $x$ & $\mathrm{x}$ & $x$ & $\mathrm{x}$ \\
\hline & $3 \mathrm{~A}$ & Xo & Xo & $x$ & & Xo & $x$ & $x$ & $x$ & $x$ & & $x$ & & $x$ \\
\hline & $3 P$ & & & & & & & & & $x$ & & $x$ & & $\mathrm{X}$ \\
\hline & $4 \mathrm{R}$ & & Xo & & & & $\mathrm{X}$ & & & $x$ & $x$ & Xo & $x$ & $x$ \\
\hline & $4 \mathrm{~L}$ & & $x$ & & & & $x$ & & & & $x$ & & & $x$ \\
\hline & 5 & $x$ & & Xo & Xo & & $x$ & $x$ & Xo & Xo & $x$ & Xo & $x$ & Xo \\
\hline & 6 & $x$ & & Xo & Xo & & $\mathrm{X}$ & Xo & Xo & Xo & $x$ & Xo & $x$ & Xo \\
\hline & 7 & & & & & & & & & $x$ & $x$ & & & \\
\hline & 8 & & & & & & & & & & & & & \\
\hline & $10 R$ & & & & & & $x$ & & $x$ & $x$ & $x$ & & & \\
\hline & $10 \mathrm{~L}$ & & & & & & & & & & & & & \\
\hline & Para cardiac R & $x$ & & & & & & & & & & & & \\
\hline \multirow[t]{2}{*}{ Axillary lymph node area } & $\mathrm{R}$ & & & & & & $\mathrm{x}$ & & & & & & & \\
\hline & $\mathrm{L}$ & & & $x$ & & & $\mathrm{X}$ & & & Xo & & & & \\
\hline Internal mammary chains & $\mathrm{R}$ & & & & & & $\mathrm{X}$ & & & & & Xo & & \\
\hline
\end{tabular}


ultrasound with the calculation of the left ventricular ejection fraction (LVEF) were performed at least every year and were compared with the values obtained before irradiation.

\section{Statistical analysis}

The dosimetric parameters of each patient were compared with the non-parametric equivalent of a paired $t$-test for matched observations (Wilcoxon test). The threshold for statistical significance was $\mathrm{p}<0.05$. All statistical analyses were performed using Statview 5.1 software (version 5.1 SAS Institute In.).

\section{Results}

The median follow-up of the 13 patients was 23 months (range: 16-48). The median CTV and PTV were $272 \mathrm{~mL}$ (range: 155-950) and $970 \mathrm{~mL}$ (range: 512-2666), respectively. We observed two relapses at 15 and 28 months. The first relapse arose in a non-irradiated site (with no fixation of ${ }^{18} \mathrm{FDG}$ and no adenopathy in the first exam of the site), and the patient was treated with a new irradiation. The patient was alive at 48 months. The second relapse appeared at the irradiated site and was treated by chemotherapy. The two-year progression-free survival was $91.6 \%$, and the 2- and 3-year overall survivals were $100 \%$. The median number of LCVE controls was 2 (1-4). No cardiac dysfunction was observed, with a mean LVEF of 63\% (60$70)$ before irradiation and $63 \%(55-72)$ at the last control. The median number of LFT was 2 (1-4). No change of the LFT at 1 year was observed, and no patient complained of breath dysfunction.

\section{Dose distribution}

\section{Target dosimetry (Table 2)}

The conformity index was better for IMRT than for 3DCRT, at 1.2 and 2.4 , respectively $(\mathrm{p}=0.001)$. The median cover index was 0.8 (range: $0.4-08$ ) for IMRT and 0.6 (range 07-0.9) for 3D-CRT ( $\mathrm{p}=0.001)$. The homogeneity indices were not significantly different between the two plans. The mean V95\% values for IMRT and 3D-CRT were 95.8\% (range: 94.1-99.4\%) and 93.7\% (range: 76.8$97.8 \%$ ), respectively, with no significant difference between the two plans. The IMRT plans resulted in significantly lower D2\% values compared with 3D-CRT, at 102.9\% (range: $103.7-108.6 \%$ ) and 105\% (range: 101.6-105.8\%), respectively $(\mathrm{p}=0.002)$. The $\mathrm{D} 50 \%$ and $\mathrm{D} 98 \%$ were not significantly different between IMRT and 3D-CRT.

\section{Breasts (Table 3, Figures 1A, 2)}

For both breast volumes, the median maximal dose was significantly lower for IMRT than for 3D-CRT, at $35.3 \mathrm{~Gy}$ and $38.6 \mathrm{~Gy}$, respectively $(\mathrm{p}=0.001)$. However, the median mean dose was significantly higher for IMRT: 4.7 Gy compared with 2.7 Gy for 3D-CRT ( $=0.05$ ). As expected, the volumes receiving the highest dose were lower for IMRT; we observed a crossing of the mean DVH curves at 16 Gy (Figure 1). For both breasts, the volume distribution was significantly better for 3D-CRT from 1 to 11 Gy $(\mathrm{p} \leq 0.05)$ and for IMRT from 19 to 36 Gy ( $\mathrm{p} \leq 0.04$ ). Additionally, the median $V_{20 G y}, V_{25 G y}$ and $V_{30 G y}$ values were significantly lower for IMRT compared with 3D-CRT at 3.9\% and $5.7 \%(\mathrm{p}=0.002), 1.2 \%$ and $5 \%(\mathrm{p}=0.001)$, and $0.2 \%$ and $4 \%(\mathrm{p}=0.001)$, respectively. However, the $\mathrm{V}_{5 \mathrm{~Gy}}$ was significantly higher for IMRT compared with 3D-CRT, at $27 \%$ and $9.9 \%(\mathrm{p}=0.001)$, respectively.

\section{Lung (Table 3, Figure 1B)}

The mean average and maximal doses were significantly higher for 3D-CRT than for IMRT, at 12.4 and 38.4 Gy and 9.7 and 36.9 Gy, respectively ( $\mathrm{p}=0.003$ for both). The mean $V_{20 G y}$ and $V_{30 G y}$ were significantly higher for 3D-CRT than for IMRT, at 30.3 and $22.1 \%$ and 15.5 and $5.3 \%$, respectively ( $\mathrm{p}=0.001$ for both). However, the mean $\mathrm{V}_{5 \text { Gy }}$ was significantly lower for 3D-CRT than for IMRT, at $46.3 \%$ and $57.7 \%$, respectively ( $\mathrm{p}=0.001$ ). The lung volumes receiving doses from 1 to 8 Gy were significantly lower for 3D-RT ( $=0.02)$. Between 9 and $11 \mathrm{~Gy}$, the volume distributions were not significantly different. Between 12 and $36 \mathrm{~Gy}$, the lung volumes were significantly lower for IMRT ( 150.01$)$. The curves intersected at a dose of 10 Gy.

\section{Heart (Table 3, Figure 1C)}

The mean average dose was significantly higher for 3DCRT than for IMRT, at 13.9 and 11.5 Gy, respectively ( $\mathrm{p}=$ 0.01 ), although the maximal dose was significantly lower for 3D-CRT than for IMRT, at 37.1 Gy and 38 Gy, respectively $(p=0.01)$. The mean $V_{20 G y}$ and $V_{30 G y}$ were significantly higher for 3D-CRT than for IMRT, at 35.7 and 29\% and 25 and $14.4 \%$, respectively $(\mathrm{p}=0.002$ and $\mathrm{p}=0.001$, respectively). The heart volumes receiving doses of 1 or 2 Gy were significantly lower for 3D-RT $(\mathrm{p}<0.009)$. Between 3 and $11 \mathrm{~Gy}$ and for 35 and $36 \mathrm{~Gy}$, the mean volume distributions were not significantly different. Between 12 and $34 \mathrm{~Gy}$, the mean volume distributions were significantly lower for IMRT ( $\mathrm{p}$ 0.04). The curves intersected at a dose of $7 \mathrm{~Gy}$.

\section{Esophagus (Table 3, Figure 1D)}

The mean average dose was significantly higher for 3DCRT than for IMRT, at 24.6 and 21.5 Gy, respectively ( $\mathrm{p}=$ 0.002 ). The mean maximal doses were not significantly different for 3D-CRT and for IMRT. The mean $\mathrm{V}_{35 \mathrm{~Gy}}$ was significantly higher for 3D-CRT than for IMRT, at $41 \%$ and $28.5 \%$, respectively $(\mathrm{p}=0.02)$. Between 1 and 9 Gy and for $36 \mathrm{~Gy}$, the mean volume distributions were not significantly different. Between 10 and $35 \mathrm{~Gy}$, the mean volume distributions were significantly lower for IMRT ( $\leq 0.04)$. The curves intersected at a dose of 6 Gy. 
Table 2 PTV dose-constraints and indexes for each patient

\begin{tabular}{|c|c|c|c|c|c|c|c|c|c|c|c|c|c|c|}
\hline \multirow[t]{2}{*}{ Patient } & \multicolumn{2}{|c|}{ V95\% } & \multicolumn{2}{|c|}{ D98\% } & \multicolumn{2}{|c|}{ D50\% } & \multicolumn{2}{|c|}{ D2\% } & \multicolumn{2}{|c|}{$\mathrm{Cl}$} & \multicolumn{2}{|c|}{$\mathrm{HI}$} & \multicolumn{2}{|c|}{$\mathrm{CO}$} \\
\hline & 3D-CRT & IMRT HT & 3D-CRT & IMRT HT & 3D-CRT & IMRT HT & 3D-CRT & IMRT HT & 3D-CRT & IMRT HT & 3D-CRT & IMRT HT & 3D-CRT & IMRT HT \\
\hline 1 & 95.6 & 96.2 & 91.3 & 93.05 & 102 & 99.9 & 106.6 & 104.1 & 2.3 & 1.2 & 1.1 & 1.1 & 0.6 & 0.8 \\
\hline 2 & 96.8 & 94,9 & 92.9 & 90.7 & 100.7 & 99.9 & 104.7 & 102.8 & 2.4 & 1.1 & 1.1 & 1.1 & 0.7 & 0.8 \\
\hline 3 & 92.3 & 98.1 & 82.5 & 95.2 & 100 & 100 & 104.4 & 103.05 & 2.3 & 1.3 & 1.1 & 1.1 & 0.5 & 0.7 \\
\hline 4 & 94.3 & 99.4 & 92.3 & 97.8 & 99.4 & 100.1 & 107.3 & 102.1 & 2.8 & 1.3 & 1.1 & 1.1 & 0.8 & 0.9 \\
\hline 5 & 91.9 & 97.5 & 90.4 & 94.4 & 99.1 & 99.8 & 105 & 102.3 & 2.3 & 1.3 & 1.1 & 1.1 & 0.6 & 0.7 \\
\hline 6 & 76.8 & 94.6 & 86.3 & 90.6 & 97.7 & 101.2 & 104.7 & 105.8 & 2.6 & 1.3 & 1.1 & 1.1 & 0.4 & 0.7 \\
\hline 7 & 94.5 & 95.3 & 88.1 & 92.3 & 103.05 & 100 & 106 & 101.6 & 2.8 & 1.1 & 1.2 & 1.1 & 0.6 & 0.8 \\
\hline 8 & 92.2 & 94.9 & 87.5 & 91.1 & 101.6 & 100 & 108.6 & 102.9 & 2.4 & 1.1 & 1.1 & 1.1 & 0.5 & 0.7 \\
\hline 9 & 96.1 & 94.3 & 93.3 & 90.5 & 99.6 & 99.7 & 103.7 & 102.9 & 2.4 & 1.1 & 1.1 & 1.1 & 0.6 & 0.8 \\
\hline 10 & 94.1 & 96.8 & 90.8 & 93 & 99.8 & 99.7 & 104.5 & 102.5 & 2.3 & 1.3 & 1.1 & 1.1 & 0.7 & 0.7 \\
\hline 11 & 97.8 & 94.1 & 94.6 & 90 & 101.7 & 99.8 & 104.9 & 103 & 3.1 & 1.1 & 1.1 & 1.1 & 0.5 & 0.7 \\
\hline 12 & 97.2 & 95.1 & 93.7 & 91.6 & 102 & 100 & 106.6 & 103.4 & 3.0 & 1.1 & 1.1 & 1.1 & 0.8 & 0.8 \\
\hline 13 & 97.7 & 94.5 & 94.5 & 90.5 & 101.4 & 99.8 & 105.4 & 102.9 & 3.0 & 1.2 & 1.1 & 1.1 & 0.8 & 0.8 \\
\hline mean & 93.7 & 95.8 & 90.6 & 92.4 & 100.6 & 100 & 105.6 & 103 & 2.6 & 1.2 & 1.1 & 1.1 & 0.6 & 0.8 \\
\hline median & 94.5 & 95.1 & 91.3 & 91.6 & 100.7 & 99.9 & 105 & 102.9 & 2.4 & 1.2 & 1.1 & 1.1 & 0.6 & 0.8 \\
\hline (p) & \multicolumn{2}{|c|}{ NS } & \multicolumn{2}{|c|}{ NS } & \multicolumn{2}{|c|}{ NS } & \multicolumn{2}{|c|}{0.002} & \multicolumn{2}{|c|}{0.001} & \multicolumn{2}{|c|}{ NS } & \multicolumn{2}{|c|}{0.001} \\
\hline
\end{tabular}


Table 3 Dose-comparisons into organs at risk according to radiation therapy technique

\begin{tabular}{|c|c|c|c|c|c|c|}
\hline \multicolumn{2}{|c|}{ Factors / Dose (Gy) } & \multicolumn{2}{|c|}{ 3D-CRT } & \multicolumn{2}{|c|}{ IMRT } & \multirow[t]{2}{*}{$(p)$} \\
\hline & & Median & Mean & Median & Mean & \\
\hline \multirow[t]{7}{*}{ Breasts } & Dmax & 38.6 & 38.3 & 35.3 & 33.6 & 0.001 \\
\hline & Dmin & 0.001 & 0.02 & 0.3 & 0.8 & 0.001 \\
\hline & Dmean & 2.7 & 4.9 & 4.7 & 5.7 & 0.05 \\
\hline & V5 Gy & 9.9 & 17.2 & 27 & 32.7 & 0.001 \\
\hline & V20 Gy & 5.7 & 11.6 & 3.9 & 9.1 & 0.002 \\
\hline & V25 Gy & 5.05 & 10.4 & 1.2 & 4.6 & 0.001 \\
\hline & V30 Gy & 4.05 & 8.9 & 0.2 & 2.6 & 0.001 \\
\hline \multirow[t]{7}{*}{ Right breast } & Dmax & 37.7 & 34.6 & 32.7 & 30.3 & 0.01 \\
\hline & $\overline{D m i n}$ & 0.001 & 0.02 & 0.3 & 0.8 & 0.001 \\
\hline & Dmean & 2.1 & 3.8 & 4.4 & 5.2 & 0.007 \\
\hline & V5 Gy & 7.8 & 13.1 & 25.5 & 29.7 & 0.001 \\
\hline & V20 Gy & 4.3 & 8.5 & 2.6 & 7.8 & NS \\
\hline & V25 Gy & 3.5 & 7.5 & 1.04 & 4.3 & 0.004 \\
\hline & V30 Gy & 2.7 & 6.4 & 0.2 & 2.3 & 0.002 \\
\hline \multirow[t]{7}{*}{ Left breast } & Dmax & 38.3 & 35.5 & 34 & 31.8 & 0.02 \\
\hline & Dmin & 0.001 & 0.08 & 0.3 & 1.5 & 0.001 \\
\hline & Dmean & 3.2 & 6 & 4.6 & 6.2 & NS \\
\hline & $\overline{V 5} G y$ & 11.1 & 21.3 & 31.8 & 35.8 & 0.007 \\
\hline & V20 Gy & 6.4 & 14.4 & 3.6 & 10.1 & 0.002 \\
\hline & V25 Gy & 5.5 & 13 & 1.5 & 4.9 & 0.002 \\
\hline & V30 Gy & 4.4 & 11.1 & 0.4 & 2.8 & 0.002 \\
\hline \multirow[t]{6}{*}{ Lung-PTV } & Dmax & 38.6 & 38.4 & 36.8 & 36.9 & 0.003 \\
\hline & Dmin & 0.1 & 0.2 & 0.3 & 0.7 & 0.002 \\
\hline & Dmean & 12 & 12.4 & 9.2 & 9.7 & 0.003 \\
\hline & V5 Gy & 47.1 & 46.3 & 56.4 & 57.7 & 0.001 \\
\hline & V20 Gy & 28.2 & 30.3 & 12.2 & 15.5 & 0.001 \\
\hline & V30 Gy & 19.4 & 22.1 & 4.9 & 5.3 & 0.001 \\
\hline \multirow[t]{5}{*}{ Heart } & Dmax & 37.3 & 37.1 & 38.1 & 38 & 0.01 \\
\hline & Dmin & 0.3 & 0.6 & 0.7 & 1.3 & 0.001 \\
\hline & Dmean & 13 & 13.9 & 11.2 & 11.5 & 0.01 \\
\hline & V20 Gy & 32.3 & 35.7 & 20.7 & 25 & 0.002 \\
\hline & V30 Gy & 23.1 & 29 & 11.1 & 14.4 & 0.001 \\
\hline \multirow[t]{4}{*}{ Oesophagus } & Dmax & 37.3 & 37.3 & 36.9 & 36.9 & NS \\
\hline & Dmin & 0.4 & 3.0 & 0.8 & 1.7 & 0.02 \\
\hline & Dmean & 23.3 & 24.6 & 20.8 & 21.5 & 0.002 \\
\hline & V35 Gy & 48.4 & 41 & 26.7 & 28.5 & 0.02 \\
\hline \multirow[t]{4}{*}{ Thyroid } & Dmax & 37.2 & 37.2 & 36.9 & 37.1 & NS \\
\hline & $\overline{D \min }$ & 3.4 & 13.9 & 12.6 & 15.1 & NS \\
\hline & Dmean & 34.6 & 30.1 & 31.6 & 29.4 & NS \\
\hline & V30 Gy & 87.7 & 75.1 & 72.7 & 64.1 & 0.003 \\
\hline Integral dose & Mean (Gy.L) & - & 179.0 & - & 176.8 & NS \\
\hline
\end{tabular}

\section{Discussion}

This study reports a dosimetric comparison of a series of 13 women with bulky early-stage Hodgkin lymphoma treated with INRT and IMRT using tomotherapy. This study is the third publication comparing IMRT and conformal 3D radiotherapy; a case report previously compared both techniques [41], and one series of 10 women comparing four irradiation plans was recently published [8]. In our series, the volumes were large (bulky tumors) and needed extensive radiation fields, leading to a difficult conformal treatment able to spare numerous organs at risk, such as the heart, lung, thyroid and spine. All plan comparisons were performed before the treatment, and overall the patients were treated with IMRT. Because of the excellent outcome of the patients with early-stage Hodgkin disease and the known risk of ionizing radiation, decreasing the treatment was performed. A decrease in the total dose was the first step [23]; the second step was the adaptation of the irradiated volume from the involved fields to the initial involved node areas [3,29,30,42-44]. A "Mantelet" field was progressively avoided. The last step to improve the dose distribution was the use of IMRT or proton therapy or of respiratory gating [24,25,30,45-49]. All these techniques aim to achieve better homogeneity of the target dose distribution, which we proved in our study as the conformity index was reduced by a factor of 2 between 3D-CRT and IMRT.

However, the treatment remains challenging. A recently published trial demonstrated that a combination of ABVD and radiotherapy improved disease-free survival compared with ABVD alone but that the overall survival was worse in the combination group [50]. The main reason for the increase in mortality with the combination treatment was the excess of causes of death other than Hodgkin disease in the combined treatment group [50]. The doses and radiation technique could be responsible for this loss of survival. However, in that study, the RT-fields used in the RT-arm were outdated, i.e., subtotal nodal irradiation, which is known to contribute to increase morbidity and 


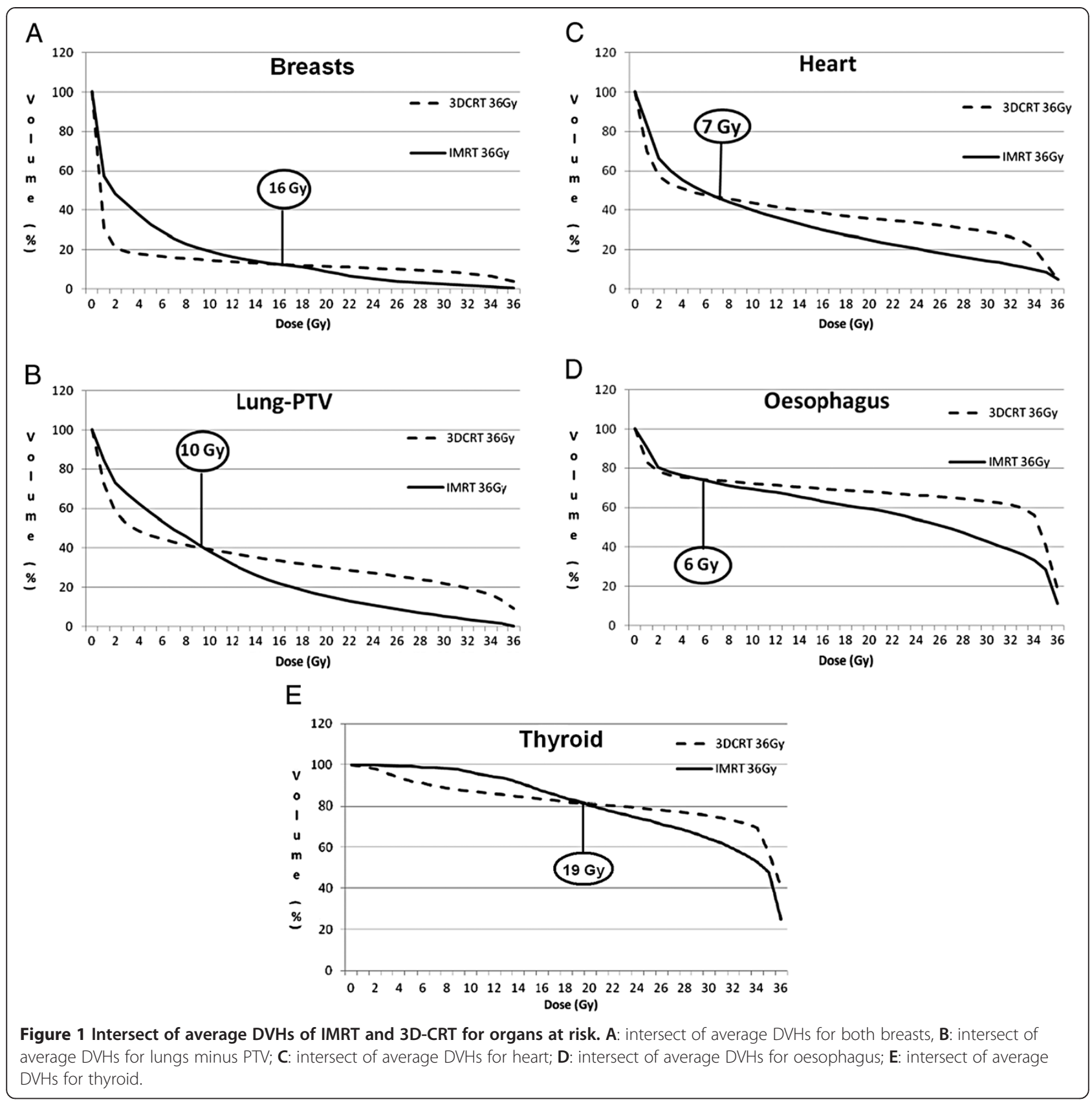

mortality from cardio-toxicity and secondary cancers. Moreover, many of the deaths in the radiotherapy arm were clearly unrelated to radiotherapy [50]. A meta-analysis that pooled the results of trials comparing the combination of chemotherapy and radiotherapy and the same chemotherapy regimens alone showed that combined treatment was associated with a better disease-free survival and a higher survival rate. However, the chemotherapy schedules were not considered optimal [51].

The main causes of death after Hodgkin disease treatment include secondary cancers and lung and heart dysfunction. The cardiac pathologies induced by radiation are highly variable [52], and the delivered dose to the heart is a major factor of these complications [53,54]. However, the dose relationship that induces cardiac morbidity and cancer is a matter of debate as there is sufficient evidence to suggest a linear dose-response for cardiac mortality [55], with doses $<5$ Gy most likely being less at risk than higher doses [56]. Decreasing the dose to the heart is a major goal, which can be reached with IMRT, even if the NTCP (normal tissue complication probability) is low at these doses [41].

For solid secondary neoplasms, breast and lung cancers are the most frequent types of malignant tumor [10,57]. 


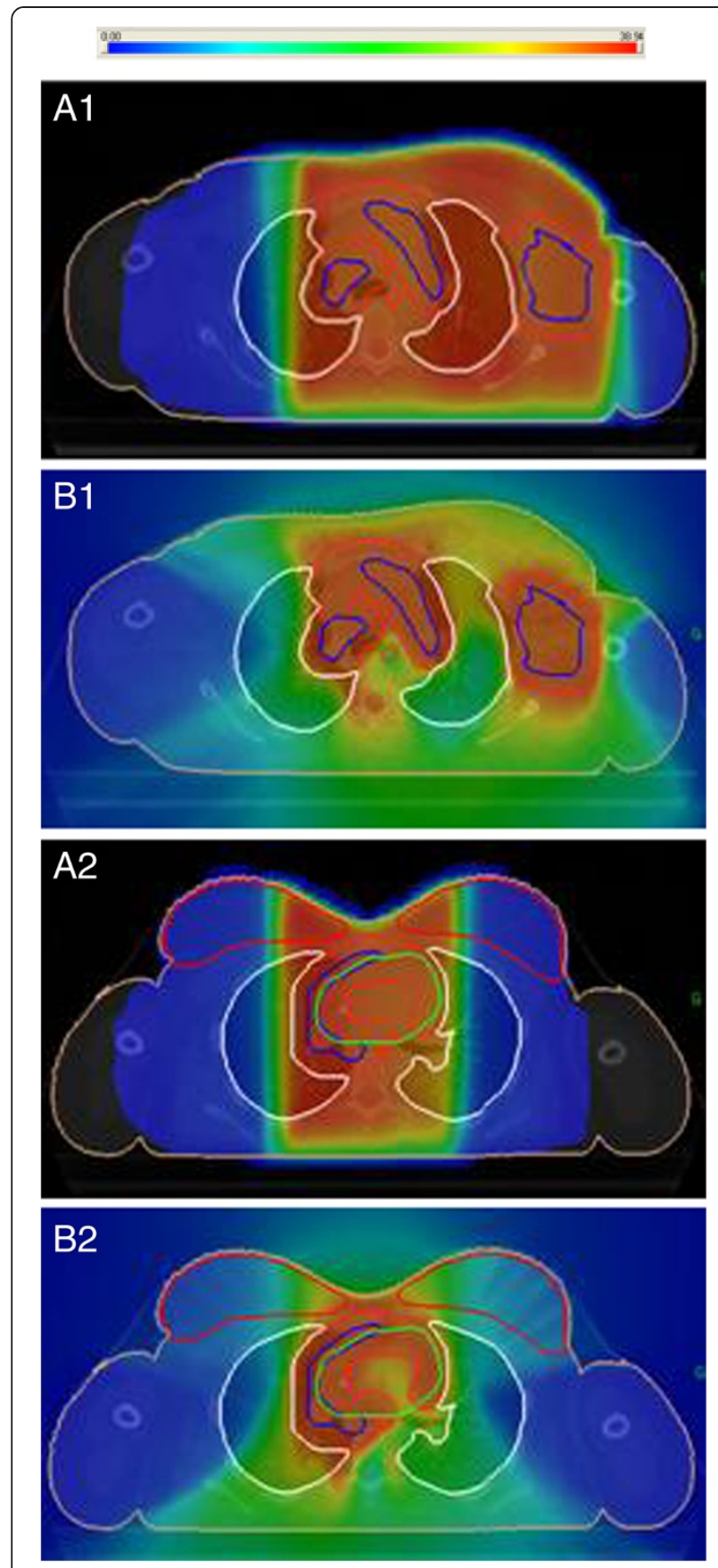

Figure 2 Dose distribution for the 3D-CRT (A1-A2) and IMRT techniques (B1-B2).

The increase in the risk for breast cancer has been well described [58-64]. The roles of dose [64], volume [65] and age $[10,16]$ are well known. The risk of secondary lung cancer is related to the combined treatment and, specifically for radiotherapy, the function of the dose and irradiated volume $[66,67]$. The dose-response relationships for secondary cancers also suggest a linear dose-response, with the exception of thyroid cancer $[57,64]$.
The follow-up of the patients in this series could be considered to be short, but the risk of relapse is always quick; although we treated large tumors, we did not observe an increase in the relapse rate. Paumier et al. published comparable results with a longer follow-up [24,25]. Our series is the first study of women treated with tomotherapy IMRT, and we can suggest some conclusions. As expected, IMRT with tomotherapy decreased the median conformity index by twice, from 2.4 for 3D-CRT to 1.2 with IMRT, a highly significant difference. IMRT is feasible and well tolerated in terms of clinical tolerance and heart and pulmonary functions. Large doses were clearly demonstrated as responsible for the complications after Hodgkin disease. The dose distributions were clearly improved by IMRT. This improvement was obtained mainly for the higher doses that cause heart morbidity and induce cancer. For the breasts, doses greater than $20 \mathrm{~Gy}$ are at risk of inducing cancer. Van Leeuwen et al. showed a significantly higher breast cancer risk in patients receiving radiotherapy alone at a dose of $\geq 24$ Gy [64]. Bhatia et al. also demonstrated that young patients given $<20 \mathrm{~Gy}$ to the breasts did not have a significantly higher risk of breast cancer compared with the controls [10]. The $V_{20 G y}$, $\mathrm{V}_{25 \text { Gy }}$ and $\mathrm{V}_{30 \text { Gy }}$ were $1.5,2.5$ and 3.5 times lower, respectively, for IMRT than for 3D-CRT. For the lung tissues, the $\mathrm{V}_{20 \text { Gy }}$ and $\mathrm{V}_{30 \text { Gy }}$ were 2 times and 4.5 times lower, respectively, for IMRT than for 3D-CRT. For the heart, the $\mathrm{V}_{20 \text { Gy }}$ and $\mathrm{V}_{30 \text { Gy }}$ were 1.4 and 2 times lower, respectively, for IMRT than for 3D-CRT. For the esophagus, the $\mathrm{V}_{35 \mathrm{~Gy}}$ was 1.7 lower for IMRT than for 3D-CRT, and for the thyroid, the $\mathrm{V}_{30 \text { Gy }}$ was 1.2 lower for IMRT. Based on this list of classical constraints to critical organs, we demonstrated that IMRT can deliver a higher dose to the PTV and successfully decrease the highest dose in all the critical organs at risk of secondary cancer or dysfunction. The values of lung $\mathrm{V}_{20 \text { Gy }}$ and heart $\mathrm{V}_{30 \text { Gy }}$ were comparable with those previously published $[8,24,41,48]$.

However, controlling the secondary appearance of breast cancer by ultrasound $\mathrm{CT}$ and magnetic resonance imaging beginning at least five to eight years after the completion of radiation therapy is recommended. For lung cancer, preventing smoking is recommended. Interestingly, the risk of mortality using the estimated 20-year survival for patients with solid secondary cancer was shown to be $72 \%$ compared with $80 \%$ for those who did not develop any secondary cancer, which was not significantly different [57]. Furthermore, a recently published study reported that conservative treatment followed by irradiation can be efficiently performed in patients with breast cancer after Hodgkin disease [68].

Some discussions have criticized the risk of secondary cancer with respect to the "bath" of low-to-moderate doses delivered to the patient's body [49]. However, some arguments can reassure patients and physicians. 
The first complication in Hodgkin disease in cases similar to those in our series is cardiac side effects up to cardiac death. The decrease in the dose in this organ at risk is assumed to decrease the chance of this type of death or morbidity. The same conclusion can be reached for lung function complications. Some authors have translated the decrease in the dose in NTCP (normal tissue complication probabilities), showing the clear impact of the decrease in the dose in lowering complications [41,48].

Notably, the question of radiation-induced carcinogenesis remains controversial. In particular, the phenomenon of radiation hormesis at low radiation doses has attracted increasing attention [69]. Radiation hormesis is considered to be an adaptive response to the external stress of radiation exposure and is manifested in several cell lines in the form of reduced chromosomal aberrations and increased longevity.

Recently, Weber et al. showed by calculating the excess relative risk that decreasing the irradiation fields leads to a dramatic decrease in radiation-induced cancer. However, for comparable irradiation fields, the risks appeared higher for IMRT than for 3D-CRT. These calculations have been performed with linear and non-linear models, taking into account mainly the low dose volume risk [8]. However, two major clinical series for breast cancer demonstrated a dose-risk relationship $[63,64]$. Furthermore, clinical data have suggested that only a minority of tumors developed inside $(<10 \%)$ or outside $(11 \%)$ the PTV [70,71]. Rather, the majority of secondary cancers have been observed within the margin of the PTV [71] or at the field periphery $[71,72]$. This region of the dose or penumbra is rarely studied in the dose distribution and can highly vary according to the photon energy used for irradiation. This observation could suggest that radiation-induced cell death becomes dominant over carcinogenic mutations radiation dose increases. This hypothesis, thus, appears to contrast with the dose reduction developed recently and to not correlate with the clinical observation of Kirova et al., who showed that the dose levels at which secondary cancers are most likely to occur have not yet been clearly established. The authors showed that most reported cases of radiationinduced sarcomas after breast irradiation occurred at sites that had received doses of 60-80 Gy, with a minimal dose of 10 Gy [9].

Extrapolating the risk of radiation-induced carcinogenesis is an uncertain exercise. Data on radiation carcinogenesis are mainly derived from retrospective studies, with variable patient populations exposed to variable radiation doses with dosimetry that is often uncertain. In addition, a heightened risk of secondary malignancies may exist in these patients. In an extensive review of the literature, Suit et al. concluded that the experimentally observed heterogeneity in the induced secondary cancer risk indicated a large genetic role in the determination of risk in the individual [73]. Furthermore, due to the quite large and undefined heterogeneity in the patient populations studied, no precise quantification of the risk of radiation-induced secondary cancer is available at present [73]. Most of these series had difficulties in differentiating the pathological subtypes and dose distributions, which seems to be important data to take into account to ameliorate the predictive analysis. With respect to the risk of complications, a large series of children treated with ionizing radiation demonstrated that the risk of cancer induction was not clearly related to the dose. One third of those cancers arose in areas that received a low dose, one third in areas receiving a moderate doses, and one third in areas receiving a high dose [74]. In our series, specially conducted in women, we showed that IMRT was able to significantly avoid large tissue volumes receiving moderate to large doses at the cost of increasing the volume receiving a low dose. However, the integral dose is not increased by the IMRT technique with tomotherapy compared with 3D-CRT, as shown previously $[41,75]$.

Another factor of confusion could have appeared because decreasing the dose to non-tumoral tissues will likely lead to a decrease in radiation-related non-cancerous disease. Thus, the absolute number of cancers could increase in the future by improving the survival of the global population.

A better understanding of the dose distributions and inducible secondary cancer for each organ is necessary to perform dosimetry with real dose constraints to protect against the development of secondary cancers. Additionally, a prudence principle is required. With respect to this goal, radiation oncologists are able to demonstrate some advantages of IMRT compared with 3D-RT.

\section{Conclusion}

IMRT is an elegant treatment to irradiate large Hodgkin disease in women. It allows good local control to be achieved and has no acute side effects. Because of the decrease in the higher dose in most organs at risk, this therapy will hopefully decrease late complications. However, a longer follow-up is needed to definitively evaluate such an outcome.

\section{Consent}

Written informed consent was obtained from the patient.

\section{Competing interests}

The authors declare that they have no competing interests.

\section{Authors' contributions}

DA collected data, performed analysis and wrote article. GN design the study, analysed data and wrote article. PM, CN calculated dosimetries. All authors read and approved the final manuscript.

\section{Author details}

${ }^{1}$ Radiotherapy department, Centre de lutte contre le Cancer Paul Strauss, 3 , rue de la Porte de l'Hôpital, Strasbourg Cedex BP 42, 67065, France. 
2Department of Hematology and Oncology, Hôpital Civil, 1 place de I'Hôpital, Strasbourg 67098, France. ${ }^{3}$ Nuclear Medicine department, Centre de lutte contre le Cancer Paul Strauss, 3, rue de la Porte de l'Hôpital, Strasbourg Cedex BP 42, 67065, France.

Received: 6 October 2012 Accepted: 16 April 2013 Published: 2 May 2013

\section{References}

1. Bonadonna G, Bonfante V, Viviani S, Di Russo A, Villani F, Valagussa P: ABVD plus subtotal nodal versus involved-field radiotherapy in early-stage Hodgkin's disease: long-term results. J Clin Oncol 2004, 22(14):2835-2841.

2. Engert A, Franklin J, Eich HT, Brillant C, Sehlen S, Cartoni C, Herrmann R, Pfreundschuh M, Sieber M, Tesch $\mathrm{H}$, et al: Two cycles of doxorubicin, bleomycin, vinblastine, and dacarbazine plus extended-field radiotherapy is superior to radiotherapy alone in early favorable Hodgkin's lymphoma: final results of the GHSG HD7 trial. J Clin Oncol 2007, 25(23):3495-3502.

3. Ferme C, Eghbali H, Meerwaldt JH, Rieux C, Bosq J, Berger F, Girinsky T, Brice $P$, van't Veer MB, Walewski JA, et al: Chemotherapy plus involved-field radiation in early-stage Hodgkin's disease. N Engl J Med 2007, 357(19):1916-1927.

4. Noordijk EM, Carde P, Dupouy N, Hagenbeek A, Krol AD, Kluin-Nelemans JC, Tirelli U, Monconduit M, Thomas J, Eghbali H, et al: Combined-modality therapy for clinical stage I or II Hodgkin's lymphoma: long-term results of the European Organisation for Research and Treatment of Cancer H7 randomized controlled trials. J Clin Oncol 2006, 24(19):3128-3135.

5. Oeffinger KC, Mertens AC, Sklar CA, Kawashima T, Hudson MM, Meadows AT, Friedman DL, Marina N, Hobbie W, Kadan-Lottick NS, et al: Chronic health conditions in adult survivors of childhood cancer. N Engl I Med 2006, 355(15):1572-1582

6. Meadows AT, Obringer AC, Marrero O, Oberlin O, Robison L, Fossati-Bellani F, Green D, Voute PA, Morris-Jones P, Greenberg M, et al: Second malignant neoplasms following childhood Hodgkin's disease: treatment and splenectomy as risk factors. Med Pediatr Oncol 1989, 17(6):477-484.

7. Moser EC, Noordijk EM, van Leeuwen FE, le Cessie S, Baars JW, Thomas J, Carde P, Meerwaldt JH, van Glabbeke M, Kluin-Nelemans HC: Long-term risk of cardiovascular disease after treatment for aggressive non-Hodgkin lymphoma. Blood 2006, 107(7):2912-2919.

8. Weber DC, Johanson S, Peguret N, Cozzi L, Olsen DR: Predicted risk of radiation-induced cancers after involved field and involved node radiotherapy with or without intensity modulation for early-stage hodgkin lymphoma in female patients. Int J Radiat Oncol Biol Phys 2011, 81(2):490-497.

9. Kirova YM, Vilcoq JR, Asselain B, Sastre-Garau X, Fourquet A: Radiation-induced sarcomas after radiotherapy for breast carcinoma: a large-scale single-institution review. Cancer 2005, 104(4):856-863.

10. Bhatia S, Robison LL, Oberlin O, Greenberg M, Bunin G, Fossati-Bellani F, Meadows AT: Breast cancer and other second neoplasms after childhood Hodgkin's disease. N Engl J Med 1996, 334(12):745-751.

11. Swerdlow AJ, Barber JA, Hudson GV, Cunningham D, Gupta RK, Hancock BW, Horwich A, Lister TA, Linch DC: Risk of second malignancy after Hodgkin's disease in a collaborative British cohort: the relation to age at treatment. J Clin Oncol 2000, 18(3):498-509.

12. Green DM, Hyland A, Barcos MP, Reynolds JA, Lee RJ, Hall BC, Zevon MA: Second malignant neoplasms after treatment for Hodgkin's disease in childhood or adolescence. J Clin Oncol 2000, 18(7):1492-1499.

13. Henderson TO, Whitton J, Stovall M, Mertens AC, Mitby P, Friedman D, Strong LC, Hammond S, Neglia JP, Meadows AT, et al: Secondary sarcomas in childhood cancer survivors: a report from the Childhood Cancer Survivor Study. J Natl Cancer Inst 2007, 99(4):300-308.

14. Mertens AC, Yasui Y, Neglia JP, Potter JD, Nesbit ME Jr, Ruccione K Smithson WA, Robison LL: Late mortality experience in five-year survivors of childhood and adolescent cancer: the Childhood Cancer Survivor Study. J Clin Oncol 2001, 19(13):3163-3172.

15. Neglia JP, Friedman DL, Yasui Y, Mertens AC, Hammond S, Stovall M, Donaldson SS, Meadows AT, Robison LL: Second malignant neoplasms in five-year survivors of childhood cancer: childhood cancer survivor study. J Natl Cancer Inst 2001, 93(8):618-629.

16. Ng AK, Bernardo MV, Weller E, Backstrand K, Silver B, Marcus KC, Tarbell NJ, Stevenson MA, Friedberg JW, Mauch PM: Second malignancy after
Hodgkin disease treated with radiation therapy with or without chemotherapy: long-term risks and risk factors. Blood 2002, 100(6):1989-1996.

17. Robertson CM, Hawkins MM, Kingston JE: Late deaths and survival after childhood cancer: implications for cure. BMJ 1994, 309(6948):162-166.

18. van Leeuwen FE, Klokman WJ, Veer MB, Hagenbeek A, Krol AD, Vetter UA, Schaapveld M, van Heerde P, Burgers JM, Somers R, et al: Long-term risk of second malignancy in survivors of Hodgkin's disease treated during adolescence or young adulthood. J Clin Oncol 2000, 18(3):487-497.

19. Sankila R, Garwicz S, Olsen JH, Dollner H, Hertz H, Kreuger A, Langmark F, Lanning M, Moller T, Tulinius H: Risk of subsequent malignant neoplasms among 1,641 Hodgkin's disease patients diagnosed in childhood and adolescence: a population-based cohort study in the five Nordic countries. Association of the Nordic Cancer Registries and the Nordic Society of Pediatric Hematology and Oncology. J Clin Oncol 1996, 14(5):1442-1446

20. Clemons M, Loijens L, Goss P: Breast cancer risk following irradiation for Hodgkin's disease. Cancer Treat Rev 2000, 26(4):291-302.

21. Bhatia S, Sather HN, Pabustan OB, Trigg ME, Gaynon PS, Robison LL: Low incidence of second neoplasms among children diagnosed with acute lymphoblastic leukemia after 1983. Blood 2002, 99(12):4257-4264.

22. Girinsky T, Ghalibafian M: Radiotherapy of hodgkin lymphoma: indications, new fields, and techniques. Semin Radiat Oncol 2007, 17(3):206-222.

23. Engert A, Plutschow A, Eich HT, Lohri A, Dorken B, Borchmann P, Berger B, Greil R, Willborn KC, Wilhelm M, et al: Reduced treatment intensity in patients with early-stage Hodgkin's lymphoma. N Engl J Med 2010, 363(7):640-652.

24. Paumier A, Ghalibafian M, Beaudre A, Ferreira I, Pichenot C, Messai T, Lessard NA, Lefkopoulos D, Girinsky T: Involved-node radiotherapy and modern radiation treatment techniques in patients with Hodgkin lymphoma. Int J Radiat Oncol Biol Phys 2011, 80(1):199-205.

25. Paumier A, Ghalibafian M, Gilmore J, Beaudre A, Blanchard P, el Nemr M, Azoury F, al Hamokles H, Lefkopoulos D, Girinsky T: Dosimetric benefits of intensity-modulated radiotherapy combined with the deep-inspiration breath-hold technique in patients with mediastinal Hodgkin's lymphoma. Int J Radiat Oncol Biol Phys 2012, 82(4):1522-1527.

26. Press OW, LeBlanc $M$, Lichter AS, Grogan TM, Unger JM, Wasserman $T H$, Gaynor ER, Peterson BA, Miller TP, Fisher RI: Phase III randomized intergroup trial of subtotal lymphoid irradiation versus doxorubicin, vinblastine, and subtotal lymphoid irradiation for stage IA to IIA Hodgkin's disease. J Clin Oncol 2001, 19(22):4238-4244.

27. Mountain CF, Dresler CM: Regional lymph node classification for lung cancer staging. Chest 1997, 111(6):1718-1723.

28. Commowick O, Gregoire V, Malandain G: Atlas-based delineation of lymph node levels in head and neck computed tomography images. Radiother Oncol 2008, 87(2):281-289.

29. Girinsky T, Specht L, Ghalibafian M, Edeline V, Bonniaud G, Van Der Maazen $R$, Aleman B, Paumier A, Meijnders $P$, Lievens $Y$, et al: The conundrum of Hodgkin lymphoma nodes: to be or not to be included in the involved node radiation fields. The EORTC-GELA lymphoma group guidelines. Radiother Oncol 2008, 88(2):202-210.

30. Girinsky $T$, van der Maazen R, Specht L, Aleman B, Poortmans P, Lievens $Y$, Meijnders P, Ghalibafian M, Meerwaldt J, Noordijk E: Involved-node radiotherapy (INRT) in patients with early Hodgkin lymphoma: concepts and guidelines. Radiother Oncol 2006, 79(3):270-277.

31. Girinsky T, Ghalibafian M, Bonniaud G, Bayla A, Magne N, Ferreira I, Lumbroso J: Is FDG-PET scan in patients with early stage Hodgkin lymphoma of any value in the implementation of the involved-node radiotherapy concept and dose painting? Radiother Oncol 2007, 85(2):178-186.

32. Prescribing, recording and reporting photon beam therapy. Bethesda USA: ICRU Report 50; 1993.

33. Prescribing, recording and reporting photon beam therapy. Bethesda USA: ICRU (supplement to ICRU report 50), report 62; 1999.

34. J ICRUPrescribing, Recording, and Reporting Intensity-Modulated Photon-Beam Therapy (IMRT)(ICRU Report 83) ICRU Report 83, (Supplement to ICRU Report 50). 2010, 10.

35. Feuvret L, Noel G, Mazeron JJ, Bey P: Conformity index: a review. Int $\mathrm{J}$ Radiat Oncol Biol Phys 2006, 64(2):333-342.

36. Graham MV, Purdy JA, Emami B, Harms W, Bosch W, Lockett MA, Perez CA Clinical dose-volume histogram analysis for pneumonitis after $3 \mathrm{D}$ 
treatment for non-small cell lung cancer (NSCLC). Int J Radiat Oncol Biol Phys 1999, 45(2):323-329.

37. Marks LB: Dosimetric predictors of radiation-induced lung injury. Int J Radiat Oncol Biol Phys 2002, 54(2):313-316.

38. Marks LB, Bentzen SM, Deasy JO, Kong FM, Bradley JD, Vogelius IS, EI Naqa I, Hubbs JL, Lebesque JV, Timmerman RD, et al: Radiation dosevolume effects in the lung. Int J Radiat Oncol Biol Phys 2010, 76(3 Suppl):S70-76.

39. Marks LB, Yorke ED, Jackson A, Ten Haken RK, Constine LS, Eisbruch A, Bentzen SM, Nam J, Deasy JO: Use of normal tissue complication probability models in the clinic. Int J Radiat Oncol Biol Phys 2010, 76(3 Suppl):S10-19.

40. Seppenwoolde Y, Lebesque JV, de Jaeger K, Belderbos JS, Boersma LJ, Schilstra C, Henning GT, Hayman JA, Martel MK, Ten Haken RK: Comparing different NTCP models that predict the incidence of radiation pneumonitis. Normal tissue complication probability. Int J Radiat Oncol Biol Phys 2003, 55(3):724-735.

41. Vlachaki M, Castellon I, Leite C, Perkins T, Ahmad S: Impact of respiratory gating using 4-dimensional computed tomography on the dosimetry of tumor and normal tissues in patients with thoracic malignancies. Am J Clin Oncol 2009, 32(3):262-268.

42. Yahalom J, Mauch P: The involved field is back: issues in delineating the radiation field in Hodgkin's disease. Ann Oncol 2002 13(Suppl 1):79-83.

43. Maraldo MV, Aznar MC, Vogelius IR, Petersen PM, Specht L: Involved node radiation therapy: an effective alternative in early-stage hodgkin lymphoma. Int J Radiat Oncol Biol Phys 2013, 85(4):1057-1065.

44. Eich HT, Muller RP, Engenhart-Cabillic R, Lukas P, Schmidberger H, Staar S, Willich N: Involved-node radiotherapy in early-stage Hodgkin's lymphoma. Definition and guidelines of the German Hodgkin Study Group (GHSG). Strahlenther Onkol 2008, 184(8):406-410.

45. Girinsky $T$, van der Maazen $R$, Specht $L$, Aleman B, Poortmans $P$, Lievens $Y$, Meijnders P, Ghalibafian M, Meerwaldt J, Noordijk E: Involved-node radiotherapy (INRT) in patients with early Hodgkin lymphoma: concepts and guidelines. Radiotherapy and oncology: journal of the European Society for Therapeutic Radiology and Oncology 2006, 79(3):270-277.

46. Ghalibafian M, Beaudre A, Girinsky T: Heart and coronary artery protection in patients with mediastinal Hodgkin lymphoma treated with intensity-modulated radiotherapy: dose constraints to virtual volumes or to organs at risk? Radiotherapy and oncology: journal of the European Society for Therapeutic Radiology and Oncology 2008, 87(1):82-88

47. Chera BS, Rodriguez C, Morris CG, Louis D, Yeung D, Li Z, Mendenhall NP: Dosimetric comparison of three different involved nodal irradiation techniques for stage II Hodgkin's lymphoma patients: conventional radiotherapy, intensity-modulated radiotherapy, and three-dimensional proton radiotherapy. Int J Radiat Oncol Biol Phys 2009, 75(4):1173-1180.

48. Cella L, Liuzzi R, Magliulo M, Conson M, Camera L, Salvatore M, Pacelli R: Radiotherapy of large target volumes in Hodgkin's lymphoma: normal tissue sparing capability of forward IMRT versus conventional techniques. Radiat Oncol 2010, 5:33.

49. Tubiana M: Can we reduce the incidence of second primary malignancies occurring after radiotherapy? A critical review. Radiother Oncol 2009, 91(1):4-15. discussion 11-13.

50. Meyer RM, Gospodarowicz MK, Connors JM, Pearcey RG, Wells WA, Winter JN, Horning SJ, Dar AR, Shustik C, Stewart DA, et al: ABVD alone versus radiation-based therapy in limited-stage Hodgkin's lymphoma. N Engl J Med 2012, 366(5):399-408.

51. Herbst C, Rehan FA, Skoetz N, Bohlius J, Brillant C, Schulz H, Monsef I, Specht $L$, Engert A: Chemotherapy alone versus chemotherapy plus radiotherapy for early stage Hodgkin lymphoma. Cochrane Database Syst Rev 2011, 2, CD007110.

52. Ng AK: Review of the cardiac long-term effects of therapy for Hodgkin lymphoma. Br J Haematol 2011, 154(1):23-31.

53. Castellino SM, Geiger AM, Mertens AC, Leisenring WM, Tooze JA, Goodman P, Stovall M, Robison LL, Hudson MM: Morbidity and mortality in long-term survivors of Hodgkin lymphoma: a report from the Childhood Cancer Survivor Study. Blood 2011, 117(6):1806-1816.

54. Rademaker J, Schoder H, Ariaratnam NS, Strauss HW, Yahalom J, Steingart R, Oeffinger KC: Coronary artery disease after radiation therapy for Hodgkin's lymphoma: coronary CT angiography findings and calcium scores in nine asymptomatic patients. AJR Am J Roentgenol 2008, 191(1):32-37.

55. McGale P, Darby SC, Hall P, Adolfsson J, Bengtsson NO, Bennet AM, Fornander $T$, Gigante $B$, Jensen MB, Peto $R$, et al: Incidence of heart disease in 35,000 women treated with radiotherapy for breast cancer in Denmark and Sweden. Radiother Oncol 2011, 100(2):167-175

56. Chung E, Corbett JR, Moran JM, Griffith KA, Marsh RB, Feng M, Jagsi R, Kessler ML, Ficaro EC, Pierce L: Is there a dose-response relationship for heart disease with low-dose radiation therapy? Int J Radiat Oncol Biol Phys 2013, 85(4):959-964.

57. Constine LS, Tarbell N, Hudson MM, Schwartz C, Fisher SG, Muhs AG, Basu SK, Kun LE, Ng A, Mauch P, et al: Subsequent malignancies in children treated for Hodgkin's disease: associations with gender and radiation dose. Int J Radiat Oncol Biol Phys 2008, 72(1):24-33.

58. Alm El-Din MA, Hughes KS, Finkelstein DM, Betts KA, Yock TI, Tarbell NJ, Aisenberg AC, Taghian AG: Breast cancer after treatment of Hodgkin's lymphoma: risk factors that really matter. Int J Radiat Oncol Biol Phys 2009, 73(1):69-74.

59. Gervais-Fagnou DD, Girouard C, Laperriere N, Pintillie M, Goss PE: Breast cancer in women following supradiaphragmatic irradiation for Hodgkin's disease. Oncology 1999, 57(3):224-231.

60. Hancock SL, Tucker MA, Hoppe RT: Breast cancer after treatment of Hodgkin's disease. J Natl Cancer Inst 1993, 85(1):25-31.

61. Tinger A, Wasserman TH, Klein EE, Miller EA, Roberts T, Piephoff JV, Kucik $N A$ : The incidence of breast cancer following mantle field radiation therapy as a function of dose and technique. Int J Radiat Oncol Biol Phys 1997, 37(4):865-870.

62. Travis LB: Evaluation of the risk of therapy-associated complications in survivors of Hodgkin lymphoma. Hematology Am Soc Hematol Educ Program 2007, 1:192-196.

63. Travis LB, Hill DA, Dores GM, Gospodarowicz M, van Leeuwen FE, Holowaty E, Glimelius B, Andersson M, Wiklund T, Lynch CF, et al: Breast cancer following radiotherapy and chemotherapy among young women with Hodgkin disease. JAMA 2003, 290(4):465-475.

64. van Leeuwen FE, Klokman WJ, Stovall M, Dahler EC, van't Veer MB, Noordijk EM, Crommelin MA, Aleman BM, Broeks A, Gospodarowicz M, et al: Roles of radiation dose, chemotherapy, and hormonal factors in breast cancer following Hodgkin's disease. J Natl Cancer Inst 2003, 95(13):971-980

65. Franklin J, Pluetschow A, Paus M, Specht L, Anselmo AP, Aviles A, Biti G, Bogatyreva T, Bonadonna G, Brillant $C$, et al: Second malignancy risk associated with treatment of Hodgkin's lymphoma: meta-analysis of the randomised trials. Ann Oncol 2006, 17(12):1749-1760.

66. Swerdlow AJ, Schoemaker MJ, Allerton R, Horwich A, Barber JA Cunningham D, Lister TA, Rohatiner AZ, Vaughan Hudson G, Williams MV, et al: Lung cancer after Hodgkin's disease: a nested case-control study of the relation to treatment. J Clin Oncol 2001, 19(6):1610-1618.

67. Travis LB, Gospodarowicz M, Curtis RE, Clarke EA, Andersson M, Glimelius B, Joensuu T, Lynch CF, van Leeuwen FE, Holowaty E, et al: Lung cancer following chemotherapy and radiotherapy for Hodgkin's disease. J Natl Cancer Inst 2002, 94(3):182-192.

68. Haberer S, Belin L, Le Scodan R, Kirova YM, Savignoni A, Stevens D, Moisson P, Decaudin D, Pierga JY, Reyal F, et al: Locoregional treatment for breast carcinoma after Hodgkin's lymphoma: the breast conservation option. Int J Radiat Oncol Biol Phys 2012, 82(2):e145-152.

69. Renner R: Hormesis. Nietzsche's toxicology. Sci Am 2003, 289(3):28-30.

70. Epstein R, Hanham I, Dale R: Radiotherapy-induced second cancers: are we doing enough to protect young patients? Eur J Cancer 1997, 33(4) 526-530.

71. Dorr W, Herrmann T: Second primary tumors after radiotherapy for malignancies. Treatment-related parameters. Strahlenther Onkol 2002, 178(7):357-362.

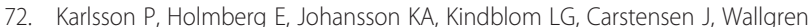
A: Soft tissue sarcoma after treatment for breast cancer. Radiother Oncol 1996, 38(1):25-31.

73. Suit H, Goldberg S, Niemierko A, Ancukiewicz M, Hall E, Goitein M, Wong W, Paganetti $\mathrm{H}$ : Secondary carcinogenesis in patients treated with radiation: a review of data on radiation-induced cancers in human, non-human primate, canine and rodent subjects. Radiat Res 2007, 167(1):12-42. 
74. Diallo I, Haddy N, Adjadj E, Samand A, Quiniou E, Chavaudra J, Alziar I,

Perret N, Guerin S, Lefkopoulos D, et al: Frequency distribution of second solid cancer locations in relation to the irradiated volume among 115 patients treated for childhood cancer. Int J Radiat Oncol Biol Phys 2009, 74(3):876-883.

75. Beneyton V, Niederst C, Vigneron C, Meyer P, Becmeur F, Marcellin L, Lutz P, Noel G: Comparison of the dosimetries of 3-dimensions Radiotherapy (3D-RT) with linear accelerator and intensity modulated radiotherapy (IMRT) with helical tomotherapy in children irradiated for neuroblastoma. BMC Med Phys 2012, 12:2.

doi:10.1186/1748-717X-8-112

Cite this article as: Antoni et al:: Contribution of three-dimensional

conformal intensity-modulated radiation therapy for women affected by bulky stage II supradiaphragmatic Hodgkin disease. Radiation Oncology $20138: 112$

\section{Submit your next manuscript to BioMed Central and take full advantage of:}

- Convenient online submission

- Thorough peer review

- No space constraints or color figure charges

- Immediate publication on acceptance

- Inclusion in PubMed, CAS, Scopus and Google Scholar

- Research which is freely available for redistribution 